\title{
Positional Intermixing of the Normal and the Reverse Magnetizations of the Kawajiri-misaki Basalt Lavas
}

In this paper are reported the further results on the field observation of the Kawajiri-misaki basalt lavas as a supplement to the previous data. [1] From an area of one meter square of the outcrop belonging to entirely one rock block of the lavas, the present author has sampled further specimens, 17 in number, (from No. 27 to No. 43 ), in addition to 26 specimens already reported in the previous paper [1] and has reconfirmed the fact of the positional close intermixing of the normal and the reverse magnetizations in the very outcrop.

The arrangement of the whole 43 specimens old and new in situ which he has sampled is represented in Fig. 1.

Fig. 2 is the Wulff's projections of the directions of the natural remanent magnetism (N.R.M.) of these 43 specimens and in Table 1 are shown the numerical values of the directions and intensities of the N.R.M.

As can be seen from Fig. 2 and Table 1, the directions of magnetization are normal for 7 specimens of No. 3, 16, 28, 29, 30, 32, 33 and intermediate for the specimen of No. 31, while those are all reverse for the remaining 35 specimens. It is worth noticing that 7 specimens from No. 27 to No. 33 showing the positional close intermixing of the normal and the reverse N.R.M. possess very low intensity of magnetization of the order of magnitude of $(1 \sim 2) \times 10^{-4}$ c.g.s.e.m.u./g. and their directions of magnetization are nearly intermediate, deviating greatly from the direction parallel or anti. parallel to the present geomagnetic field. The above fact of the intermediate directions of the weak N.R.M. in situ seems to be the natural consequence of the self-reversal phenomenon, as the opposite magnetization produced by the self-reversal is not

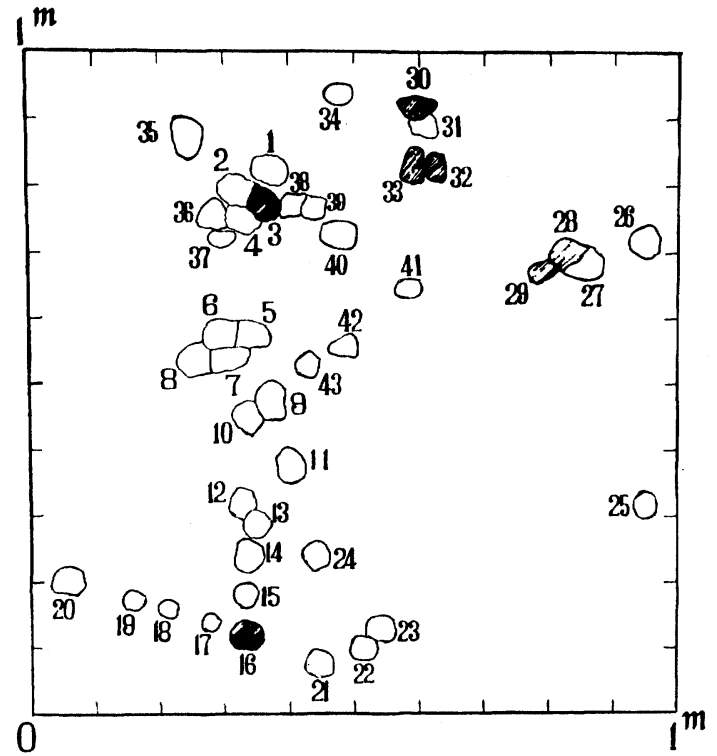

Fig. 1 The arrangement of 43 specimens sampled. No. $3,16,28,29,30,32,33$ : normal No. 31 : intermediate

The remaining 35 specimens: reverse always exactly anti-parallel to the direction of the original magnetization having taken place prior to the self-reversal phenomenon. This field evidence suggests that 


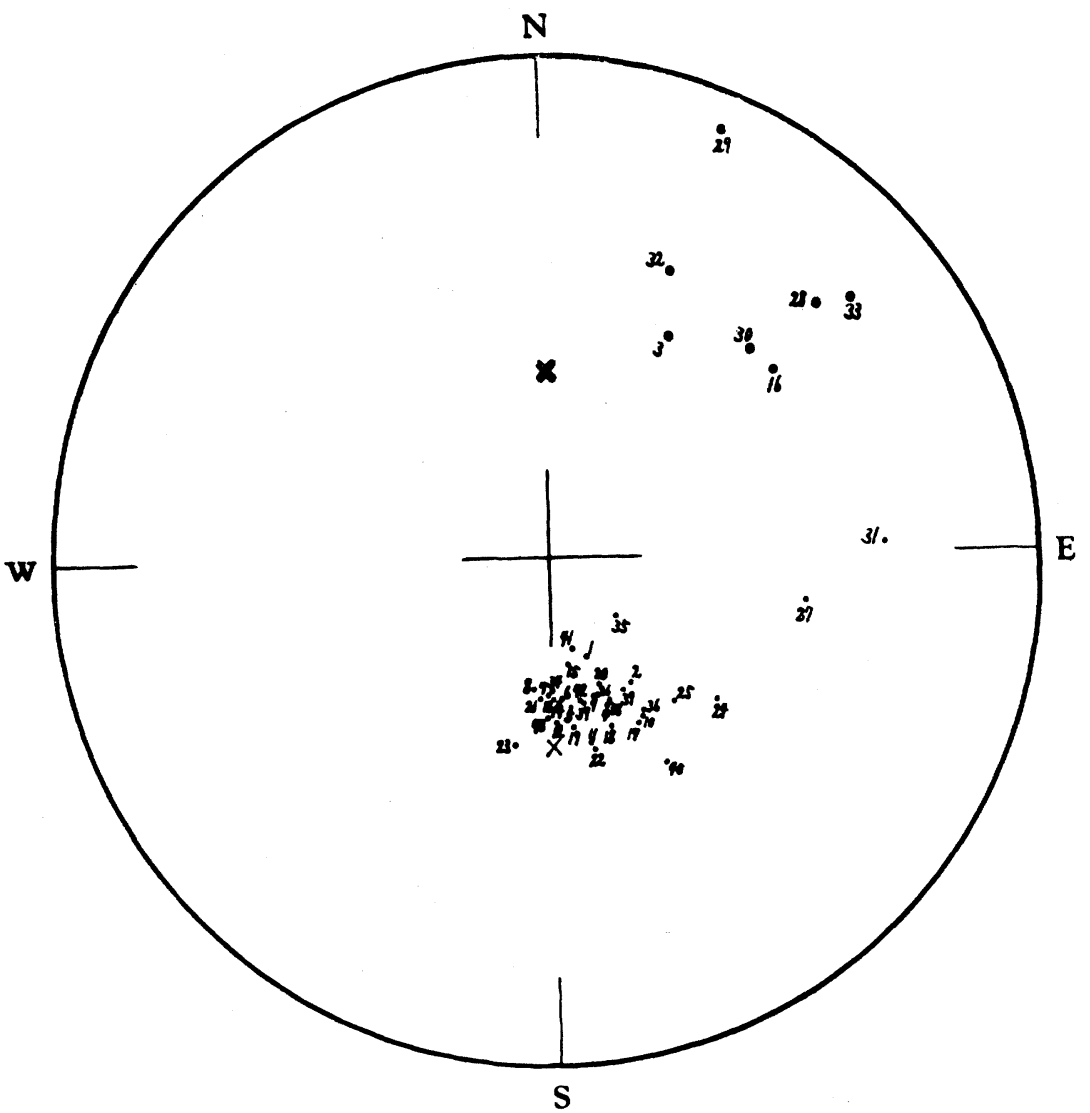

Fig. 2 Wulff's projections of the directions of the N.R.M. of 43 specimens. Big plots represent the lower hemisphere and thin the upper. The thick cross $(X)$ indicates the direction of the present geomagnetic field.

Table 1 Numerical values of the directions and intensities of the N.R.M. of 43 specimens.

The intensities of magnetization are shown with the unit of $10^{-4}$ c.g.s.e.m.u./g.

\begin{tabular}{|c|c|c|c||c|c|c|c||c|c|c|c|}
\hline $\begin{array}{c}\text { Speci- } \\
\text { men } \\
\text { No. }\end{array}$ & $\begin{array}{c}\text { Declina- } \\
\text { tion }\end{array}$ & Dip & $\begin{array}{c}\text { Inten- } \\
\text { sity }\end{array}$ & $\begin{array}{c}\text { Speci- } \\
\text { men } \\
\text { No. }\end{array}$ & $\begin{array}{c}\text { Declina- } \\
\text { tion }\end{array}$ & Dip & $\begin{array}{c}\text { Inten- } \\
\text { sity }\end{array}$ & $\begin{array}{c}\text { Speci- } \\
\text { men } \\
\text { No. }\end{array}$ & $\begin{array}{c}\text { Declina- } \\
\text { tion }\end{array}$ & Dip & $\begin{array}{c}\text { Inten- } \\
\text { sity }\end{array}$ \\
\hline 1 & $+159^{\circ}$ & $-67^{\circ}$ & 5.2 & 16 & $+52^{\circ}$ & $+29^{\circ}$ & 4.0 & 31 & $+88^{\circ}$ & $-21^{\circ}$ & 1.1 \\
2 & +147 & -57 & 2.3 & 17 & +152 & -49 & 7.8 & $(32)$ & +25 & +26 & 2.1 \\
$(3$ & +30 & +36 & 1.2 & 18 & +160 & -51 & 8.2 & 33 & +51 & +12 & 2.1 \\
4 & +159 & -55 & 5.1 & 19 & +173 & -53 & 9.5 & 34 & \pm 180 & -61 & 5.6 \\
5 & +173 & -57 & 4.2 & 20 & +159 & -60 & 5.1 & 35 & +133 & -70 & 8.2 \\
6 & +176 & -59 & 5.3 & 21 & -175 & -59 & 8.8 & 36 & +149 & -51 & 7.5 \\
7 & -178 & -60 & 5.1 & 22 & +167 & -48 & 9.3 & 37 & +168 & -57 & 8.9 \\
8 & -172 & -61 & 4.0 & 23 & -168 & -49 & 9.0 & 38 & +157 & -56 & 7.8 \\
9 & +163 & -58 & 6.7 & 24 & +130 & -43 & 8.1 & 39 & +151 & -57 & 7.2 \\
10 & +150 & -50 & 5.7 & 25 & +139 & -49 & 4.7 & 40 & +151 & -40 & 7.9 \\
11 & +168 & -49 & 5.6 & 26 & +162 & -58 & 4.0 & 41 & +167 & -69 & 7.2 \\
12 & +179 & -54 & 6.1 & 27 & +100 & -34 & 1.7 & 42 & +169 & -58 & 8.3 \\
13 & \pm 180 & -59 & 6.5 & 3 & +48 & +16 & 1.3 & 43 & -178 & -55 & 10.0 \\
14 & +177 & -58 & 7.2 & 29 & +24 & +4 & 1.2 & The marks of circle (O): nor- \\
15 & +171 & -66 & 6.7 & 30 & +46 & +29 & 1.8 & mal, square $(\square)$ : intermediate. \\
\hline
\end{tabular}


the author's interpretation stated in the previous paper [1] proves to be plausible.

The author is very grateful to Prof. N. Kumagai for valuable discussions and is also indebted to Messrs. T. Nakagawa and A. Miyazaki for helps in sampling the specimens from the field.

\section{Reference}

[1] E. Asami : Journ. Geomag. Geoele., 8, 147 (1956).

Eizo ASAMI

Department of Guidance, Kvoto University 